\title{
A Comparative Study between Synthetic Fabric Patch Graft and Collagen Matrix Graft in Duraplasty
}

\author{
Shantanu Ghosh ${ }^{1}$
}

${ }^{1}$ Department of Neurosurgery, Calcutta National Medical College, Kolkata, West Bengal, India.

\section{ABSTRACT}

\section{BACKGROUND}

Watertight dural closure is a vital and desirable step following all intracerebral operations to prevent CSF leakage, consequent infection and wound dehiscence and delayed wound healing which in turn increases patient morbidity and mortality. Various autologous and synthetic materials have been tried for duraplasty. This study was done to compare two types of synthetic materials used for duraplasty.

\section{METHODS}

This randomised prospective study was done at our institute on 56 patients who underwent decompressive craniectomy. Patients were randomly divided into two groups, one group underwent duraplasty with synthetic fabric patch graft and the other group underwent duraplasty with collagen matrix graft and results were compared between the two groups.

\section{RESULTS}

Patients who underwent duraplasty with collagen matrix graft were found to have a significantly reduced operating time of nearly 34 minutes as compared to the synthetic fabric patch and also there was no incidence of CSF leakage or wound infection in those patients in whom collagen matrix was used.

\section{CONCLUSIONS}

Collagen matrix graft is far superior to synthetic fabric graft for duraplasty as it saves valuable operating time and has fewer complications as compared to synthetic fabric grafts.
Corresponding Author: Dr. Shantanu Ghosh, C/4/49, Kendriya Vihar, Kolkata - 700052,

West Bengal, India.

E-mail: shashwata_shantanu@yahoo.co.in

DOI: $10.14260 /$ jemds/2022/3

How to Cite This Article:

Ghosh S. A comparative study between synthetic fabric patch graft and collagen matrix graft in duraplasty. J Evolution Med Dent Sci 2022;11(01):13-16, DOI: 10.14260/jemds/2022/3

Submission 02-12-2021, Peer Review 30-12-2021, Acceptance 06-01-2022, Published 11-01-2022.

Copyright (c) 2022 Shantanu Ghosh. This is an open access article distributed under Creative Commons Attribution License [Attribution 4.0 International (CC BY 4.0)]

\section{KEY WORDS}

Duraplasty, Collagen Matrix Graft, Synthetic Fabric Patch Graft 


\section{BACKGROUND}

Watertight dural closure is a very crucial step in any intracerebral surgery. In 1908, Cushing stated that an accurate approximation of the dura in its two layers is desirable and should be painstakingly done. ${ }^{1}$ This statement still holds good today and watertight dural closure is desired by most neurosurgeons. Very often in intracerebral surgery primary dural closure is not possible due to brain swelling or due to a large amount of dura having been excised either because of involvement by tumour or the dura is lacerated and infected. Lax duraplasty is done to give space for the anticipated brain swelling following decompressive craniectomy. In patients requiring repeat surgery, those patients who had undergone duraplasty, dissection becomes easy and the chance of injury to the brain is prevented. Initially, duraplasty was done using autologous grafts like pericranium, temporalis fascia or fascia lata. Autologous grafts have the advantage of being non-toxic, easily available, and being natural tissue, they are rapidly integrated into natural tissue and do not induce any inflammatory or immunological reaction. Moreover, they are strong, easily sutured and of low cost.

However, the disadvantages are that they have to be harvested from a different site which increases the operating time and is also associated with donor site morbidities like infection, haematoma and postoperative pain.

Hence there were efforts to search for various synthetic materials to be used as a substitute for duraplasty. Various foreign materials were tried like bovine graft, bilayer chitosan $^{2}$ and later synthetic fabric grafts and collagen matrix grafts. ${ }^{3}$ However, some of these materials produced inflammatory host response ${ }^{4}$ and hence were discarded. Newer synthetic grafts like the synthetic fabric patch graft and the collagen matrix grafts did not produce such reactions ${ }^{5}$ and hence are now being increasingly used for duraplasty. The advantages of these grafts are that they reduce operating time, have lesser incidence of CSF leak, infection and wound dehiscence and there is less blood loss ${ }^{6}$ as compared to patients in whom the autologous graft is harvested. However, they are costly, especially collagen matrix grafts.

Some surgeons have however questioned the need for watertight closure of the dura ${ }^{7}$ and they found the same incidence of complications in those who did not undergo watertight duraplasty as compared to those with watertight duraplasty. Synthetic fabric patch is made of polypropylene while collagen matrix graft is made of type 1 collagen made from bovine achilles tendon. The collagen matrix graft is activated by fluid to create safe and temporary hydrostatic attraction between the graft and the dural margins. The collagen matrix initiates platelet aggregation and the platelets on contact with the matrix degranulate and release clotting factors that initiate fibrin clot formation and this fibrin clot creates a watertight barrier and binds the implanted matrix to the patients' dura. Within two weeks of implantation, a neomembrane is formed between the dural margins to permanently close the dural defect and after six to eight weeks the graft is resorbed and replaced by dura. At the end of one year, the neodura would have developed into mature dura. This study was done to compare two types of synthetic materials used for duraplasty.

\section{METHODS}

This double-blind randomised prospective study was done at our institute, Calcutta National Medical College between $1^{\text {st }}$ Jan 2020 and $31^{\text {st }}$ December 2020 on patients admitted to our hospital.

56 patients who underwent supratentorial decompressive craniectomies for traumatic head injuries were included in the study (sample size was calculated using the software OpenEpi) after excluding patients with associated injuries like thoracic, abdominal or long bone fractures. Patients with diabetes were also excluded as it could be a confounding factor for wound healing. These 56 patients were equally randomly assigned into two groups. One group underwent duraplasty using synthetic fabric patch while the other group underwent duraplasty using collagen matrix graft. Among these patients, we lost 6 patients in the postoperative period and they were excluded from the study. The patients were kept admitted for an average period of 10 days postoperatively. After discharge, patients were called initially after 10 days and subsequently at the one-month interval for six months.

The following data was collected about the patients' age, sex, how the trauma occurred, Glasgow Coma Scale (GCS) ${ }^{8}$ at the time of admission and at the time of discharge. Operating time from incision to completion of skin closure was noted for each patient.

Postoperatively patients were observed for CSF leakage and wound infection and dehiscence. CT scan of brain was done routinely for $48 \mathrm{hrs}$ and 7 days after the operation to look for an increase in oedema, mass effect and any subcutaneous CSF collection.

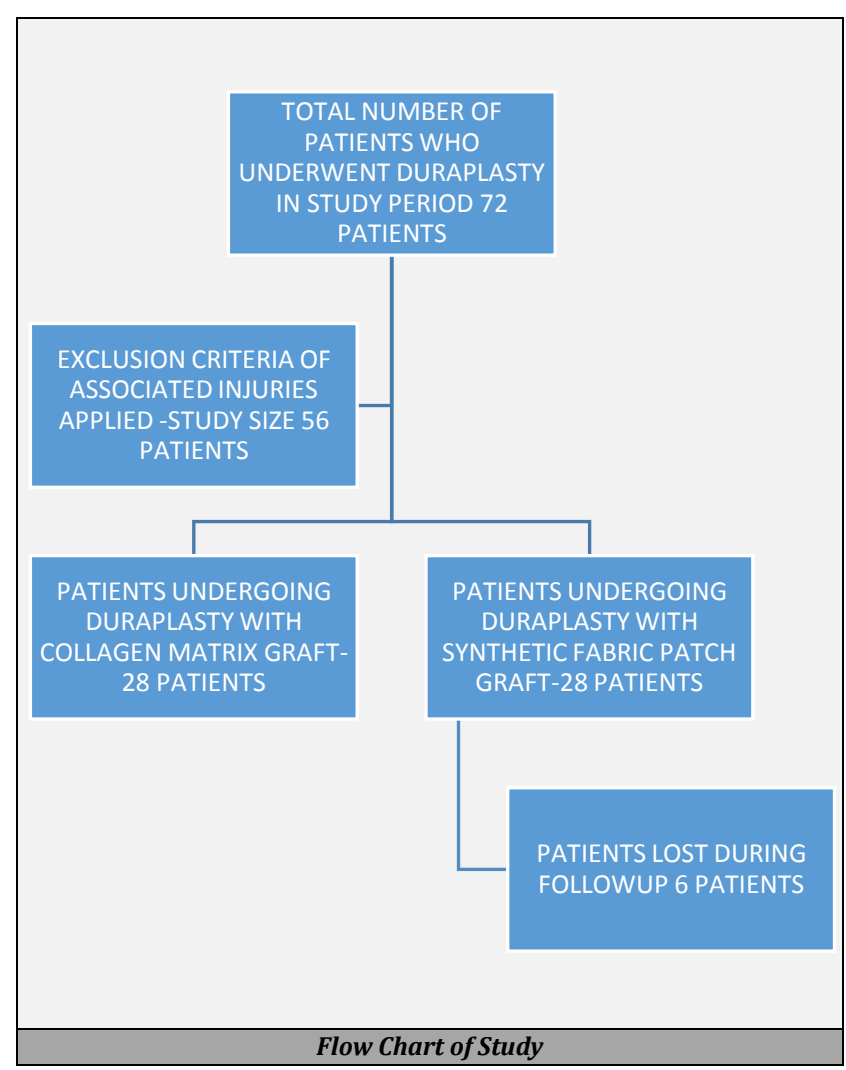

Statistical analysis was done using Epi Info software. 


\section{RESULTS}

The total number of patients in the study was 50 after applying inclusion and exclusion criteria. The findings of the study have been shown in the following tables

\begin{tabular}{|ccc|}
\hline Characteristics & Collagen Matrix Graft & Synthetic Patch Graft \\
Total Patients & 26 & 24 \\
Mean Age & 34 Years & $36 \mathrm{Yrs}$ \\
Male Pts & $22 \mathrm{Pts}$ & $21 \mathrm{Pts}$ \\
Female Pts & $4 \mathrm{Pts}$ & $3 \mathrm{Pts}$ \\
Mean GCS at Admission & 8 & 9 \\
\hline \multicolumn{2}{|c|}{ Table 1. Patient Characteristics } \\
\hline \multicolumn{2}{|c}{}
\end{tabular}

\begin{tabular}{|cc|}
\hline Road Traffic Accidents & $40 \mathrm{Pts}$ \\
Assault & $6 \mathrm{Pts}$ \\
Fall From Height & $4 \mathrm{Pts}$ \\
\hline \multicolumn{2}{|c|}{ Table 2. Nature of Trauma } \\
\hline
\end{tabular}

\begin{tabular}{|cc|}
\hline Collagen Matrix Graft & Synthetic Fabric Patch Graft \\
122 Minutes & 166 Minutes \\
Standard deviation 16.75 with a mean of & Standard deviation 14.67 with a mean of \\
122 & 166 \\
\hline Table 3. Mean Operating Time with Standard Deviation \\
\hline
\end{tabular}

\begin{tabular}{|ccc|}
\hline $\begin{array}{c}\text { Postoperative } \\
\text { Complications }\end{array}$ & $\begin{array}{c}\text { Collagen Matrix } \\
\text { Graft }\end{array}$ & $\begin{array}{c}\text { Synthetic Fabric } \\
\text { Graft }\end{array}$ \\
CSF Leak & 0 & 3 \\
Wound Infection & 0 & 3 \\
Wound Dehiscence & 0 & 2 \\
Subcutaneous CSF Accumulation & 1 & 2 \\
\hline \multicolumn{2}{|c|}{ Table 4. Postoperative Complications } \\
\hline
\end{tabular}

\begin{tabular}{|cc|}
\hline Glasgow Coma Scale & No. of Patients \\
15 & 12 \\
$13-14$ & 33 \\
$9-12$ & 5 \\
$3-8$ & 0 \\
\hline Table 5. GCS at Time of Discharge \\
\hline
\end{tabular}

\begin{tabular}{|c|c|c|}
\hline $\begin{array}{c}\text { Patient } \\
\text { Characteristics }\end{array}$ & $\begin{array}{c}\text { Collagen Matrix } \\
\text { Graft }\end{array}$ & $\begin{array}{c}\text { Synthetic Fabric } \\
\text { Patch Graft }\end{array}$ \\
\hline Age of the patients & $\begin{array}{c}\text { Standard deviation } 14.12 \\
\text { with mean } 34.07\end{array}$ & $\begin{array}{c}\text { Standard deviation } 15.76 \\
\text { with a mean of } 36\end{array}$ \\
\hline $\begin{array}{l}\text { Glasgow coma scale at } \\
\text { the time of admission }\end{array}$ & $\begin{array}{c}\text { Standard deviation } 1.88 \\
\text { with mean } 8\end{array}$ & $\begin{array}{c}\text { Standard deviation } 1.47 \\
\text { with a mean of } 9\end{array}$ \\
\hline \multicolumn{3}{|c|}{ Table 6. Statistical Analysis } \\
\hline
\end{tabular}

From the results, it can be seen that road traffic accidents are the most common causes of head injuries (80\%) and male patients are most commonly affected (86\%).

Mean operating time was found to be significantly lower (average 34 minutes) in patients who underwent duraplasty with collagen matrix graft as compared to those who underwent duraplasty with a synthetic fabric patch.

Postoperative complications like CSF leakage, wound infection and wound dehiscence and subcutaneous CSF accumulation were found to be significantly lower in those who underwent duraplasty with collagen matrix graft.

\section{DISCUSSION}

Watertight dural closure remains the goal of all the neurosurgeons though some studies have questioned the need for watertight closure and have shown similar results and complication incidence rates in patients who underwent watertight versus non-watertight closure.

Initially, autologous tissues like pericranium, fascia lata and temporalis fascia were used. These autologous tissues have numerous advantages but they have certain disadvantages like they require additional operative time to harvest the tissue and also there may be donor site morbidity. Hence autologous grafts have been replaced by synthetic grafts. Of the various synthetic grafts, synthetic fabric patch grafts were initially more widely used in our institute due to their availability and lesser cost. Later collagen matrix grafts became available and have been increasingly used by us.

Synthetic fabric patch grafts have to be sutured to the dural margins while collagen matrix grafts have to be merely placed over the dural defect and they take up the contour of the dural defect and thus effectively seal it off. It remains in place through surface tension and fibrin clot formation eliminating the need for sutures.

In our study, only one patient who underwent duraplasty with collagen matrix developed subcutaneous CSF accumulation which subsequently resolved within one month as confirmed by CT scan during his follow up at one month. There were significantly more complications in patients who underwent duraplasty with fabric patch grafts. Three of these patients developed CSF leak out of which two developed wound infection and wound dehiscence which was managed with acetazolamide.

Two other patients had subcutaneous CSF accumulation which was also resolved on conservative management. Patients who developed these complications required longer periods of hospital stay.

Longer operating time is associated with increased incidence of infection ${ }^{9}$ and is of vital importance in critical head injury patients. Also, a lesser incidence of complications means decrease in patient morbidity and mortality, along with decreasing hospital stay which helps to increase patient turnover in our overburdened hospitals.

The only disadvantage of collagen matrix graft is its significantly greater cost as compared to fabric patch grafts. However, this is offset by savings in operating time and lower incidence of complications and reduced hospital stay.

Similar results have been found in other studies which compared temporalis fascia graft with collagen matrix grafts ${ }^{10}$ as well as other studies which used collagen matrix with various methods of fixation. ${ }^{11}$

\section{CONCLUSIONS}

Duraplasty using collagen matrix grafts are far superior to fabric patch grafts as they reduce operating time significantly and also have far less incidence of postoperative complications like CSF leakage, infection and wound dehiscence.

Data sharing statement provided by the authors is available with the full text of this article at jemds.com.

Financial or other competing interests: None.

Disclosure forms provided by the authors are available with the full text of this article at jemds.com.

\section{REFERENCES}

[1] Cushing H. Surgery of the head. In: Keen WW, ed. Surgery its principles and practice. Vol. 3. Philadelphia: Saunders 1908:17-256. 
[2] Sanchez JHS, Ramos-Zuniga R, de Anda SL, et al. A new bilayer chittosan scaffolding as a dural substitute: experimental evaluation. World Neurosurg 2012;77(34)577-82.

[3] Yamada K, Miyamoto S, Nagata I et al. Development of a dural substitute from synthetic bioabsorbable polymers. J Neurosurg 1997;86(6):1012-7.

[4] Ostendorf AP, Conolly AM. Medical management of eosinophilic meningitis following bovine graft duraplasty for Chiari malformation Type 1 repair. J Neurosurg Paed 2013;12(4):357-9.

[5] Narotam PK, van Dellen JR, Bhoola KD. A clinicopathological study of collagen sponge as a dural graft in neurosurgery. J Neurosurg 1995;82(3):406-12.

[6] Algadein EA, Aleisa AA, Alsubari HI, et al. Blood loss estimation using Gauze visual analogue. Trauma Mon 2016;21(2):e34131.

[7] Barth M, Tuettenberg J, Thome C, et al. Watertight dural closure is it necessary? A prospective randomised trial in patients with supratentorial craniotomies. Neurosurgery 2008;63(4 Suppl 2):352-8.

[8] Balestreri M, Czosnyka M, Chatfield DA, et al. Predictive value of Glasgow Coma Scale after Brain trauma: change in trend over the past ten years. J Neurol Neurosurg Psychiatry 2004;75(1):161-2.

[9] Leong G, Wilson J, Charlett A. Duration of operation as a risk factor for surgical site infection: comparison of English and US data. J Hosp Infect 2006;63(3):255-62.

[10] Barooah RK, Baishya BK, Haloi H, et al. A comparative study between autologous dural closure versus collagen matrix (duragen) closure in decompressive craniectomy for trauma. Indian J Neurotrauma 2020;17(1):46-9.

[11] Stendel R, Danne M, Fiss I, et al. Efficacy and safety of a collagen matrix for cranial and spinal dural reconstruction using different fixation techniques. J Neurosurg 2008;109(2):215-21. 